\title{
A5 segment aneurysm of the anterior cerebral artery, imbedded into the body of the corpus callosum: A case report
}

\section{Fransua, Sharafeddin}

2017-02-06

Fransua , S , Hafez , A , Lehecka , M , Raj , R , Colasanti , R , Rafiel , A , Choque , J , Jahromi , B R , Niemelä , M \& Hernesniemi , J 2017 , ' A5 segment aneurysm of the anterior cerebral artery, imbedded into the body of the corpus callosum: A case report ' , Surgical Neurology International , vol. 8 , 18 . https://doi.org/10.4103/2152-7806.199559

http://hdl.handle.net/10138/232123

https://doi.org/10.4103/2152-7806.199559

publishedVersion

Downloaded from Helda, University of Helsinki institutional repository.

This is an electronic reprint of the original article.

This reprint may differ from the original in pagination and typographic detail.

Please cite the original version. 


\title{
A5 segment aneurysm of the anterior cerebral artery, imbedded into the body of the corpus callosum: A case report
}

\author{
Fransua Sharafeddin, Ahmad Hafez, Martin Lehecka, Rahul Raj, Roberto Colasanti, \\ Ahmadreza Rafiei, Joham Choque, Behnam R. Jahromi, Mika Niemelä, Juha Hernesniemi \\ Department of Neurosurgery, Helsinki University Central Hospital, Helsinki, Finland \\ E-mail: *Fransua Sharafeddin - fransua.sharafeddin@gmail.com;Ahmad Hafez - ext-ahmad.hafez@hus.fi; Martin Lehecka - martin.lehecka@hus.fi; \\ Rahul Raj - rahul.raj@hus.fi; Roberto Colasanti - roberto.colasanti@gmail.com; Ahmadreza Rafiei - ahmadreza.raf@gmail.com; \\ Joham Choque - johchove@hotmail.com; Behnam R. Jahromi - behnam.rezai@gmail.com; Mika Niemelä - mika.niemela@hus.fi; \\ Juha Hernesniemi - juha.hernesniemi@hus.fi \\ *Corresponding author \\ Received: 09 October $16 \quad$ Accepted: 07 December $16 \quad$ Published:06 February 17
}

\begin{abstract}
Background: The A5 segment aneurysms of the anterior cerebral artery are rare, approximately $0.5 \%$ of all intracranial aneurysms. They are small with a wide base located in the midline, with the domes mostly projecting upward or backward.

Case Description: The authors describe a unique case of A5 segment aneurysm, with the dome embedded into the body of the corpus callosum. This 41-year-old female was admitted to the neurology department for possible multiple sclerosis investigation. Computed tomography angiogram (CTA) revealed a 4-mm right-sided pericallosal artery aneurysm, with rare configuration, which was caudally projected, embedded into the body of the corpus callosum. Considering the family history, patient underwent a prophylactic ligation surgery. The postoperative CT and CTA showed no complication and successful occlusion of the aneurysm with no ischemia or hemorrhage in the corpus callosum.

Conclusion: To the best of our knowledge, this is the first case of an aneurysm with this configuration. Our rare case of A5 segment aneurysm demonstrates the importance of planning of the surgery, choosing the appropriate approach, and knowing the detailed anatomy of the region, as well as the necessity of microsurgical clipping of small unruptured AdistAs.
\end{abstract}

Key Words: Aneurysm, anterior cerebral artery, clipping, callosomarginal artery, corpus callosum, pericallosal artery

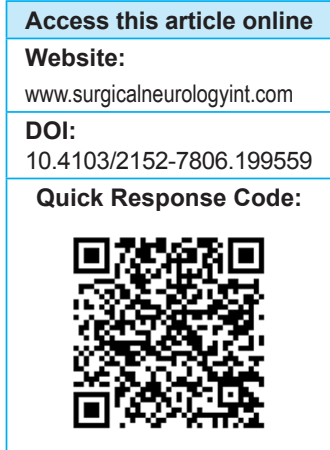

\section{INTRODUCTION}

The A5 segment aneurysms of anterior cerebral artery (ACA) are rare, approximately $0.5 \%$ of all intracranial aneurysms (IA)..$^{[1,4,5,8,10,14,17,19,21-23]}$ They are small, with wide base, located in the midline, with the domes mostly projecting upward or backward. ${ }^{[4,10,12,13,16-19]}$ In this article, we present an unusual A5 segment aneurysm with the dome embedded into the body of the corpus callosum, which, to our knowledge, is the first such case in the literature.
This is an open access article distributed under the terms of the Creative Commons Attribution-NonCommercial-ShareAlike 3.0 License, which allows others to remix, tweak, and build upon the work non-commercially, as long as the author is credited and the new creations are licensed under the identical terms.

For reprints contact: reprints@medknow.com

How to cite this article: Sharafeddin F, Hafez A, Lehecka M, Raj R, Colasanti R, Rafiei A, et al. A5 segment aneurysm of the anterior cerebral artery, imbedded into the body of the corpus callosum:A case report. Surg Neurol Int 2017;8:18. http://surgicalneurologyint.com/A5-segment-aneurysm-of-the-anterior-cerebralartery,-imbedded-into-the-body-of-the-corpus-callosum:-A case-report 


\section{CLINICAL PRESENTATION}

A 4l-year-old healthy non-smoking Caucasian female was admitted to the neurology department to be investigated for possible multiple sclerosis, vertigo, coordination problems, tingling, and numbness in her left arm. A neurological examination showed no focal abnormalities.

A computed tomography angiogram (CTA) was performed, which showed a 4-mm right-sided pericallosal artery aneurysm, with a rare configuration [Figure 1]. The right distal ACA bifurcated at the level of A4-A5 junction. The larger of the two terminal branches made a loop within the corpus callosum, where the aneurysm originated from, that was caudally projected, embedded into the body of the corpus callosum, forming a "pouch" in it [Figure 2]. The dimensions of the aneurysm were: height $-4.8 \mathrm{~mm}$; width $-4 \mathrm{~mm}$; neck $-2.8 \mathrm{~mm}$; parent artery diameter $-1.1 \mathrm{~mm}$; the depth of embedding into the corpus callosum $-7.7 \mathrm{~mm}$.

Considering the family history (mother and uncle from mother's side died from aneurysmal SAH in their forties),
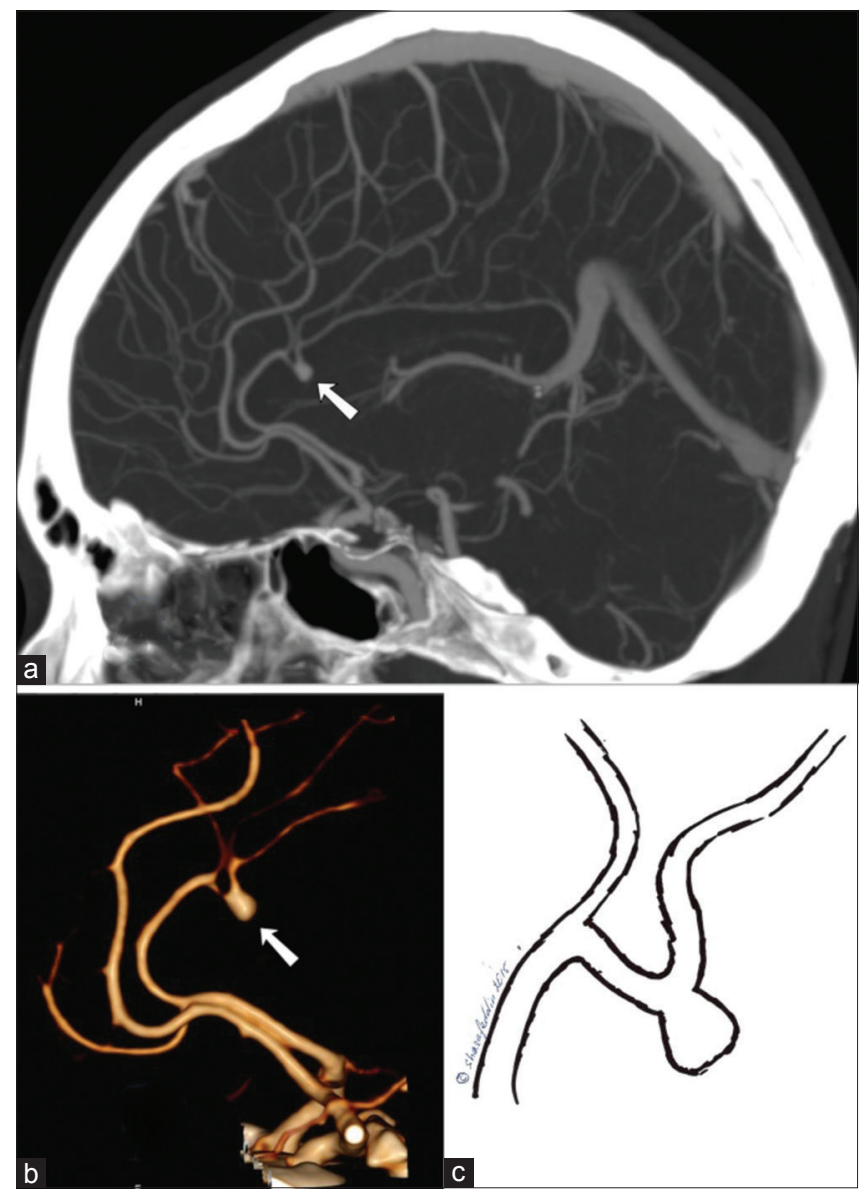

Figure I: CTA, 3D-CT, and artistic drawing, showing a $4 \mathrm{~mm}$ A5 segment aneurysm of the right ACA with rare configuration. Sagittal image (a), 3D reconstruction (b), and artistic drawing (c), showing the aneurysm (arrows) the patient was motivated for prophylactic ligation surgery.

The patient was placed in a supine position, with the head fixed in a head frame. The head was elevated $20^{\circ}$ above the heart level in neutral position with the nose pointing upward and somewhat flexed. Because of the presence of a bridging vein at the shortest trajectory projection of the aneurysm to the scull convex that was visualized at the preoperative CTA and magnetic resonance angiogram (MRA), the approach was planned frontally to the vein [Figure 3]. A slightly curved skin incision was made with its base frontally. A 1-layer skin flap was reflected frontally with spring hooks. A right paramedian frontal craniotomy was performed with bone flap placed slightly over the midline to allow better retraction of the falx medially. The dura was opened under the operating microscope as a C-shaped flap with its base at the superior sagittal sinus. After clearing the arachnoid bands interhemispheric dissection was directed along the falx toward the corpus callosum. The smaller branch of the A4 bifurcation was revealed, which was directed backward and upward. Afterward, the A4 bifurcation and the parent artery were determined beneath the smaller branch. The origin of the aneurysm was visualized, with its dome embedded into the body of the corpus callosum [Figure 4a and b]. Following careful dissection, a pilot clip was inserted to the aneurysm dome, which after reshaping of the dome by bipolar coagulation, was changed for a final clip [Figure 4c]. The second clip was applied proximal to the first one for final closure of the slightly exposed neck. For intraoperative verification of clipping, an Indocyanine Green (ICG) angiography was used.

After transferring to the intensive care unit, the patient was oriented, without any signs of neurological deficit. At first postoperative day, CT and CTA was performed, that showed no complication and successful occlusion of the aneurysm with no ischemia or hemorrhage in the corpus

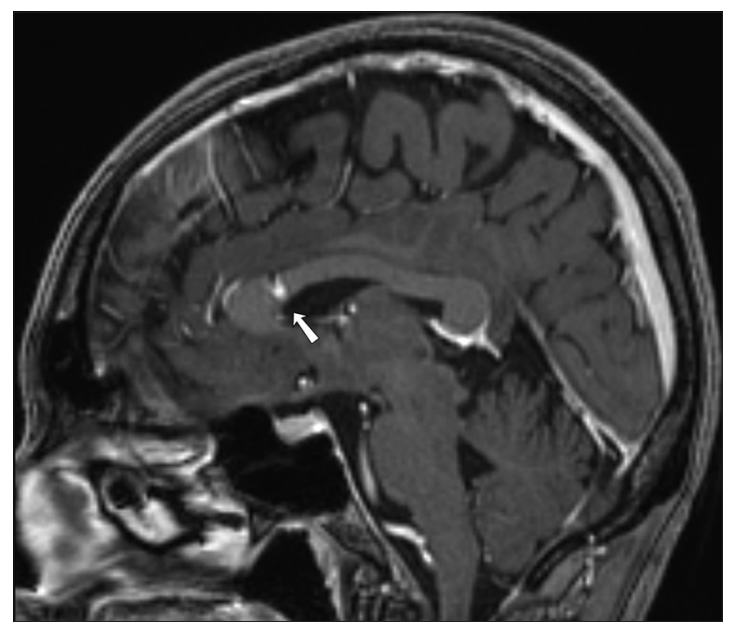

Figure 2: Sagittal MRA image showing the aneurysm imbedded into the body of the corpus callosum (arrow) 


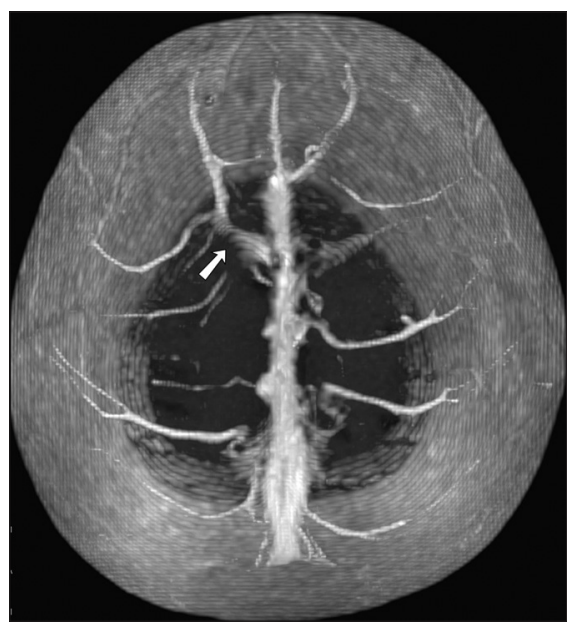

Figure 3:Axial MRA image showing the bridging vein at the shortest trajectory projection of the aneurysm to the scull convex (arrow)

callosum. The same day the patient was transferred to the ward.

\section{DISCUSSION}

According to Fischer, the ACA can be divided into 5 segments, namely, $\mathrm{Al}$ to $\mathrm{A} 5{ }^{[2]}$ The $\mathrm{A} 4$ and $\mathrm{A} 5$ are the horizontal segments of the ACA, running on the superior surface of the corpus callosum backwards in the pericallosal cistern, towards the splenum of the corpus callosum, with the coronary suture as a division point between them. ${ }^{[3,6,7,10,15,20,22]}$ Aneurysms of the A4 and A5 segments of the ACA are rare, forming approximately $0.5 \%$ of all IAs. ${ }^{[1,4,5,8,10,14,17,19,21-23]}$ The most common sites for the AdistAs are the A4 segment and the distal callosomarginal artery (CMA). The AdistAs are located in the midline, often above the free margin of the falx, which influences the side of the approach. The domes of most aneurysms distal to A3 segment of anterior cerebral artery (AdistAs) are projecting either upward or backward in the sagittal view. ${ }^{[10]}$ The main goal of the surgery of AdistAs is to select appropriate approach, locate the aneurysm inside the interhemispheric fissure, and to clip the neck without obstructing branches. ${ }^{[9-11]}$ The interhemispheric approach is used to reach the AdistAs. Because of the small size, deep location of the aneurysm, absence of any significant landmarks, it is extremely difficult to orientate inside the interhemispheric fissure and localize the aneurysm, working in the narrow corridor. Therefore, it is very important to carefully study preoperative images and to form a clear vision of a detailed course of the surgery. A4 segment and anterior portion of the A5 segment and the CMA are located below the free edge of the falx, which allows to shift the branches between two hemispheres and complicate the exposure of the AdistAs. Critical attention should be paid to this during the dissection towards the aneurysm, preventing the damage of shifting branches. A4-A5

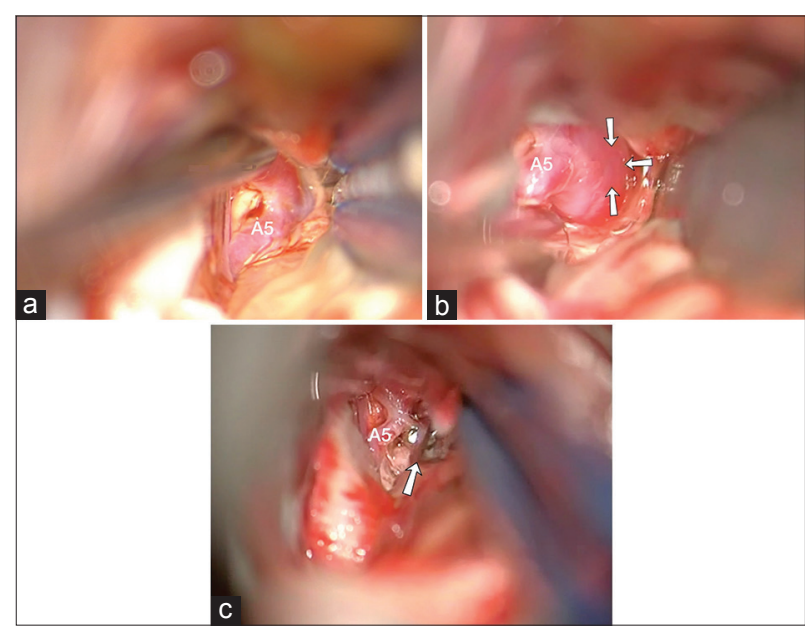

Figure 4: Intraoperative view of parent artery (a) and the origin of the aneurysm, with its dome embedded into the body of the corpus callosum (b, arrows). The final clip was inserted after reshaping of the dome by bipolar coagulation (c, arrow)

segment aneurysms are located superior to the corpus callosum, thus the surgical approach could be chosen with the shortest distance projection on the skull convex regarding the interhemispheric approach. ${ }^{[15]}$ However, the bone flap should be made taking into account the venous barriers, thus correcting the trajectory of the corridor.

\section{CONCLUSION}

To the best of our knowledge, this is the first case of an aneurysm with this configuration. Our rare case of A5 segment aneurysm demonstrates the importance of planning of the surgery, choosing the appropriate approach, and knowing the detailed anatomy of the region, as well as the necessity of microsurgical clipping of small unruptured AdistAs.

Financial support and sponsorship Nil.

Conflicts of interest

There are no conflicts of interest.

\section{REFERENCES}

I. de Sousa AA, Dantas FL, de Cardoso GT, Costa BS. Distal anterior cerebral artery aneurysms. Surg Neurol, 1999;52: I28-35.

2. Fischer E. Die Lageabweichungen der vorderen Hirnarterie im Gefassbild. Zentralbl Neurochir 1938;3:300-12.

3. Gomes FB, Dujovny M, Umansky F, Berman SK, Diaz FG, Ausman Jl, et al. Microanatomy of the anterior cerebral artery. Surg Neurol 1986;26:129-4I.

4. Hernesniemi J, Tapaninaho A, Vapalahti M, Niskanen M, Kari A, Luukkonen M. Saccular aneurysms of the distal anterior cerebral artery and its branches. Neurosurgery 1992;31:994-8.

5. Inci S, Erbengi A, Ozgen T. Aneurysms of the distal anterior cerebral artery: Report of 14 cases and a review of the literature. Surg Neurol 1998;50:130-9.

6. Kakou M, Destrieux C, Velut S. Microanatomy of the pericallosal arterial complex. J Neurosurg 2000;93:667-75.

7. Kawashima M, Matsushima T, Sasaki T. Surgical strategy for distal 
anterior cerebral artery aneurysms: Microsurgical anatomy. J Neurosurg 2003;99:517-25.

8. Laitinen L, Snellman A. Aneurysms of the pericallosal artery: A study of 14 cases verified angiographically and treated mainly by direct surgical attack. J Neurosurg 1960; 17:447-58.

9. Lehecka M, Dashti R, Hernesniemi J, Niemelä M, Koivisto T, Ronkainen A, et al. Microneurosurgical management of aneurysms at $A 3$ segment of anterior cerebral artery. Surg Neurol 2008;70:I35-5I.

I0. Lehecka M, Dashti R, Hernesniemi J, Niemelä M, Koivisto T, Ronkainen A, et al. Microneurosurgical management of aneurysms at A4 and A5 segments and distal cortical branches of anterior cerebral artery. Surg Neurol 2008;70:352-67.

II. Lehecka M, Dashti R, Hernesniemi J, Niemelä M, Koivisto T, Ronkainen A, et al. Microneurosurgical management of aneurysms at the $A 2$ segment of anterior cerebral artery (proximal pericallosal artery) and its frontobasal branches. Surg Neurol 2008;70:232-46.

I2. Lehecka M, Lehto H, Niemelä M, Juvela S, Dashti R, Koivisto T, et al. Distal anterior cerebral artery aneurysms: Treatment and outcome analysis of 50 I patients. Neurosurgery 2008;62:590-60I.

13. Mann KS, Yue CP, Wong G. Aneurysms of the pericallosal-callosomarginal junction. Surg Neurol 1984;21:26I-6.

14. Ohno K, Monma S, Suzuki R, Masaoka H, Matsushima Y, Hirakawa K. Saccular aneurysms of the distal anterior cerebral artery. Neurosurgery
1990;27:907-12.

15. Perlmutter D, Rhoton AL Jr. Microsurgical anatomy of the distal anterior cerebral artery. J Neurosurg 1978;49:204-28.

16. Proust F, Toussaint P, Hannequin D, Rabenenoïna C, Le Gars D, Fréger P. Outcome in 43 patients with distal anterior cerebral artery aneurysms. Stroke 1997;28:2405-9.

I7. Sindou M, Pelissou-Guyotat I, Mertens P, Keravel Y, Athayde AA. Pericallosal aneurysms. Surg Neurol 1988;30:434-40.

18. Snyckers FD, Drake CG. Aneurysms of the distal anterior cerebral artery. A report on 24 verified cases. S Afr Med J 1973;47:I787-91.

19. Steven DA, Lownie SP, Ferguson GG. Aneurysms of the distal anterior cerebral artery: Results in 59 consecutively managed patients. Neurosurgery 2007;60:227-33.

20. Ugur HC, Kahilogullari G, Esmer AF, Comert A, Odabasi AB, Tekdemir I, et al. A neurosurgical view of anatomical variations of the distal anterior cerebral artery:An anatomical study. J Neurosurg 2006;104:278-84.

21. Wisoff $\mathrm{JH}$, Flamm ES. Aneurysms of the distal anterior cerebral artery and associated vascular anomalies. Neurosurgery 1987;20:735-4I.

22. Yasargil MG, Carter LP. Saccular aneurysms of the distal anterior cerebral artery. J Neurosurg 1974;40:218-23.

23. Yoshimoto T, Uchida K, Suzuki J. Surgical treatment of distal anterior cerebral artery aneurysms. J Neurosurg 1979;50:40-4. 